\title{
Heritability, phenotypic and genetic correlations of size and shape of Drosophila mediopunctata wings
}

\author{
BLANCHE CHRISTINE BITNER-MATHÉ* $\uparrow \&$ LOUIS BERNARD KLACZKO \\ $\dagger$ Departamento de Genética, Instituto de Biologia, Universidade Federal do Rio de Janeiro, Caixa Postal 68011, \\ 21944-970, Rio de Janeiro-RJ, Brasil and \$Departamento de Genética e Evolução, Instituto de Biologia, \\ Universidade de Campinas, Cidade Universitária, 13083-070, Campinas-SP, Brasil
}

\begin{abstract}
We have studied the morphology of wings of Drosophila mediopunctata employing the ellipse method, a procedure that allows precise descriptions of wing size (SI), wing shape outline (SH), and placement of longitudinal wing veins. We have found that the SH and the points which determine the position of the apices of the third, fourth and fifth longitudinal wing veins show high heritability in nature (the lower bound for the natural heritability is above 0.25 ). The values found are similar to those obtained for the broad-sense heritabilities $\left(H^{2}\right)$ in the laboratory. However, SI and the point which determines the apex of the second longitudinal wing vein showed small lower bounds for heritability in nature, 0.05 and 0.07 , respectively, in spite of the high estimates of $H^{2}$ in the laboratory. These results suggest that size and shape have different genetic properties. We observed a high positive phenotypic correlation between the $\mathrm{SH}$, the fourth and the fifth longitudinal wing veins, which contrasts with a negative correlation between these traits and the second longitudinal vein. That is, as the SH gets longer, the apices of the second and fifth veins become closer to each other. Positive genetic correlations in the field were detected between $\mathrm{SH}$, the fourth and the fifth longitudinal veins and also between the third and the fourth veins.
\end{abstract}

Keywords: Drosophila, genetic correlation, heritability, size, shape, wing morphology.

\section{Introduction}

Morphological variation among natural Drosophila populations has been documented in many parts of the world, using characters correlated to body size, such as thorax and wing length. Many of these studies show latitudinal and altitudinal clines in the genetic component determining these traits in several species and continents (Prevosti, 1955; Pfriem, 1983). They are taken as evidence of the adaptive nature of changes in body size, generally explained by selection associated with temperature, as is also observed in laboratory studies (Powell, 1974). Wing shape variation is also adaptive in relation to temperature in Drosophila melanogaster (Cavicchi et al., 1991) where a differential effect on wing compartments is seen, with a greater effect on the posterior compartment than on the anterior one. Natural populations of the same species also show differences in wing shape, again mainly in the posterior compartment (Imasheva et al., 1995; Pezzoli et al.,

*Correspondence. E-mail: bcbitner@biologia.ufrj.br
1997). Thus, these studies suggest that not only wing size, but also wing shape, are important targets for natural selection.

A necessary condition for adaptive evolution is the presence of additive genetic variance in natural populations determining the trait under selection. The amount of additive genetic variance $\left(\sigma_{\mathrm{A}}^{2}\right)$ is usually expressed as its ratio to the total phenotypic variance $\left(\sigma_{\mathrm{P}}^{2}\right)$, a ratio called the narrow-sense heritability $\left(h^{2}=\sigma_{\mathrm{A} /}^{2} \sigma_{\mathrm{P}}^{2}\right)$. This determines the potential for evolutionary change of a trait and the rate at which it will respond to selection. Heritabilities for characters related to body size have been estimated in the field and significant values were found for Drosophila melanogaster (Coyne \& Beecham, 1987) and Drosophila buzzatii (Ruiz et al., 1991), and laboratory studies have shown even higher values (Weigensberg \& Roff, 1996). Pezzoli et al. (1997) obtained a large value for the broad-sense heritability for the contribution of the area of different wing regions to the total wing area. However, to our knowledge, no previous study has focused on wing shape heritability in natural populations of Drosophila. 
Besides $\sigma_{\mathrm{A}}^{2}$, another factor that affects the rate of evolution of a given trait is its genetic correlation with other traits. This is because natural selection acts on the phenotype of the whole individual, and hence the progress of selection on one trait may be affected by selection on a different genetically correlated trait. Thus, the evolution of size and shape depends not only on their $\sigma_{A}^{2}$ s, but also on the pattern of genetic covariation among all traits (Lande \& Arnold, 1983). Measuring heritabilities and genetic correlations in nature allows the estimation of the capacity of characters to evolve by natural selection and of their sensitivity to environmental variation.

The measurements taken to describe morphology are also of central importance. The better we describe morphology the better we will understand its variation. Wing size and shape have been described by choosing linear distances between landmarks in the wing, i.e. intersections of veins or junctions of veins and the contour of the wing. There are some major problems when the linear distances between these landmarks are used to describe the wing morphology: (i) it does not allow a simple geometric interpretation; (ii) changes in wing contour may be confounded with changes in wing vein displacement; and (iii) we cannot attribute the variation observed in the linear distance between any pair of veins to the displacement of one vein or the other. Other approaches to this issue include Fourier analysis (Cavicchi et al., 1991) and the estimation of the area of different wing regions and their contribution to the total area of the wing (Pezzoli et al., 1997). In a previous publication, we proposed the use of an ellipse to describe the shape of the wing outline in Drosophila (Klaczko \& BitnerMathé, 1990). This is a simple geometric method that permits an easy and precise reconstruction of wing size and shape. Changes in the placement of wing veins may also be described by the angular distance between points of junction of veins and wing contour and the major axis of the ellipse. Moreover, all measurements obtained by the ellipse method are geometrically independent.

Drosophila mediopunctata belongs to the tripunctata group of the subgenus Drosophila and has a wide geographical distribution; it has been found in many parts of Brazil (Val et al., 1981). Previous studies on this species focused on morphological and genetic aspects (see Klaczko, 1995 for a review). The objectives of the present paper are: (i) to describe the pattern of wing size and shape variation in a natural population using the ellipse method for the first time; (ii) to estimate natural heritabilities and the genetic correlations between wing size and wing shape.

\section{Materials and methods}

\section{Field collection}

Male and female Drosophila mediopunctata were collected with banana baits in July 1990 at Morro Santana, a forest area near Porto Alegre city (State of Rio Grande do Sul, Brazil; $30^{\circ} 04^{\prime} \mathrm{S} ; 51^{\circ} 19^{\prime} \mathrm{W}$ ). The females were placed individually in shell vials in a fresh culture medium and kept at constant room temperature $\left(16.5^{\circ} \mathrm{C}\right)$ to establish isofemale lines. Every day they were transferred to a new vial to avoid larval overcrowding (each vial produced fewer than 20 flies). Up to three $F_{1}$ females were taken from each isofemale strain. Each $F_{1}$ fly came from a different vial to avoid common environment effects.

\section{Wing measurements}

The right wing of each fly was dissected and mounted on a slide. Cartesian co-ordinates were taken of 40 points on the wing outline (magnified 55x) using a digitizing pad connected to a microcomputer. Then, the parameters of the ellipse were estimated (Fig. 1) as described previously (Klaczko \& Bitner-Mathé, 1990; Klaczko, 1995). Briefly, a shape-free measure of size (SI) can be obtained using the geometric mean of the two radii ( $a$ and $b$ ) of the ellipse $(\mathrm{SI}=\sqrt{ } a b)$. This measure is equal to the radius of a circle with the same area as the ellipse. On the other hand, the ratio $b / a$ is a size-free measure of an ellipse outline shape ( $\mathrm{SH})$. The ellipse can also be used to characterize the position of the points A, B, C, $\mathrm{D}, \mathrm{E}$ and $\mathrm{J}$. This is performed using the angle between the line that joins the point and the origin of the ellipse and the major axis. For example, for $\mathrm{B}$, the angle $\theta_{\mathrm{B}}$ is the angle between $\mathrm{BO}$ and the major axis, where $\mathrm{O}$ is the centre of the ellipse. Thus, the positions of those six points were measured by the angles $\theta_{\mathrm{A}}, \theta_{\mathrm{B}}, \theta_{\mathrm{C}}, \theta_{\mathrm{D}}, \theta_{\mathrm{E}}$ and $\theta_{\mathbf{J}}$.

\section{Heritability}

Wild-caught females and their daughters were used to estimate the genetic components of variance of the wing traits in the field and in the laboratory. We have assumed that the $F_{1}$ offspring from wild-caught females were full-sibs. In Drosophila melanogaster it was observed that after insemination females were unreceptive to males' attention until the depletion of the sperm saved in the spermathecae (Gromko et al., 1984).

Estimates of genetic parameters in nature should ideally be obtained by measuring relatives in the same environment. Different environments may alter the relative values of different genotypes, causing a 


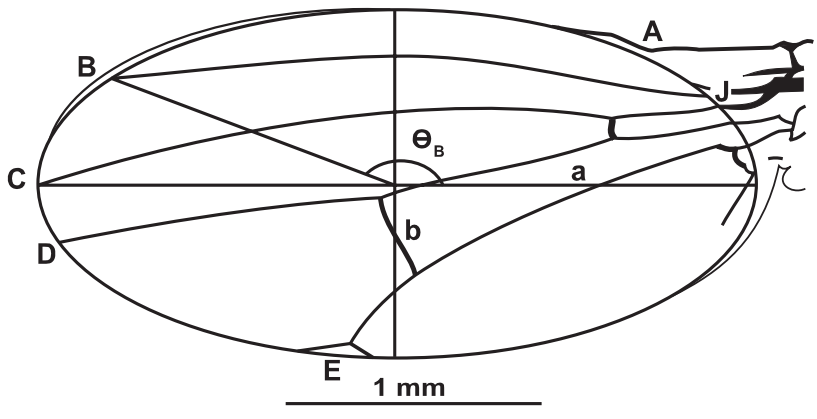

Fig. 1 Wing of Drosophila mediopunctata and adjusted ellipse. We fit the general equation of the ellipse to the Cartesian coordinates of 40 points taken from the wing outline using a least squares procedure. Solving this equation for the $x$-observed values, we calculated a correlation $(r)$ between the observed and expected $y$-values, and the centre and orientation of the ellipse found. In all cases, there was a good fit for the adjusted ellipses $(r>0.95)$. Through a translation and rotation of the coordinates system, the general equation was transformed to $x^{2} / a^{2}+y^{2} / b^{2}=1$, where $a$ and $b$ are the radii of the two director circles of the ellipse. A, B, C, D, E and J correspond to the intersection points between the longitudinal veins with the wing contour. For each of these points the position is given by the angle between the line that joins it to the centre of the ellipse and the major radius. For example, for point $\mathrm{B}$ the position is given by the angle $\theta_{\mathrm{B}}$.

genotype-by-environment interaction that can bias estimates of heritabilities and genetic correlation (Gupta \& Lewontin, 1982). However, this approach is impracticable in the case of Drosophila, as it is in many other organisms as well. To circumvent the difficulties of estimating genetic parameters in nature directly, Lande showed, in an appendix to Coyne \& Beecham (1987), that sometimes it is possible to estimate heritabilities in nature $\left(h_{\mathrm{N}}^{2}\right)$ by regressing offspring raised in the laboratory on their parents raised in the natural environment, i.e. $\beta_{(\mathrm{Ol} . \mathrm{Pn})}\left(=\sigma_{\mathrm{An}} \gamma \sigma_{\mathrm{Al}} / \sigma_{\mathrm{Pn}}^{2}\right.$, where $\gamma$ is the additive genetic correlation between the trait in nature and the same trait in laboratory; $\sigma_{\mathrm{An}}^{2}$ and $\sigma_{\mathrm{Al}}^{2}$ are the additive genetic variances in nature and in the laboratory, respectively; and $\sigma_{\mathrm{Pn}}^{2}$ is the phenotypic variance in nature). We have included families with one, two or three $F_{1}$ laboratory females and obtained a natural heritability estimate by doubling the regression coefficient of the $F_{1}$ means on their wild-caught mothers' values, i.e. $2 b_{(\mathrm{Ol} . \mathrm{Pn})}$. Differences between $\sigma_{\mathrm{A} 1}^{2}$ and $\sigma_{\mathrm{An}}^{2}$ and/or genotype-by-environment interaction $(\gamma<1)$ can bias, in either direction, the estimate of natural heritability. Riska et al. (1989) showed that it is always possible to use the cross-environment $h^{2}$ to obtain a lower bound of heritability in nature. The term $\beta_{(\mathrm{Ol} . \mathrm{Pn})}^{2}$ $\left(\sigma_{\mathrm{Pn}}^{2} / \sigma_{\mathrm{Al}}^{2}\right)=\gamma^{2} h_{N}^{2}$ gives a lower bound of $h_{\mathrm{N}}^{2}$. The lower bound of heritability in nature $\left(\gamma^{2} h_{\mathrm{N}}^{2}\right)$ was estimated here by $4 b_{(\mathrm{Ol} . \mathrm{Pn})}^{2}\left(V_{\mathrm{Pn}} / V_{\mathrm{Al}}\right)$. The squared regression coefficient was multiplied by 4 , because we have used only one parent; $V_{\mathrm{Pn}}$ is the estimate of phenotypic variance among wild-caught females and $V_{\mathrm{Al}}$ is an estimate of additive genetic variance in the laboratory obtained by doubling the covariance between the $\mathrm{F}_{1}$ female lines reared in laboratory (Becker, 1992). The estimate of the additive genetic variance by full-sib covariances $\left(C O V_{\mathrm{FS}}\right)$ in the laboratory may be inflated by dominance and maternal effects. However, in this case, the lower bound heritability becomes more conservative, unless the estimate of $\beta_{(\mathrm{Ol} . \mathrm{Pn})}$ is also affected, as by maternal effects.

\section{Phenotypic and genetic correlation}

The matrices of phenotypic correlation between wing traits were obtained from males and females in the field and from laboratory-reared $F_{1}$ females.

We have tried to identify clusters of original wing variables by applying a principal components analysis (PCA) to each of these matrices. The PCA is a method that allows one to identify the major patterns of correlations among measurements and summarize as much of the information (variation) in the data as possible in few dimensions - the principal components (PC). The coefficients of the principal components, obtained from a correlation matrix, are the correlation coefficients of each of the original variables with each component. Their square represents the fraction of the variance of each original variable explained by each of the components. They also indicate, indirectly, the relationships among the original variables themselves (Neff \& Marcus, 1980).

The genetic correlation $\left(r_{\mathrm{G}}\right)$ in nature was estimated as the arithmetic mean of two reciprocal betweentrait offspring-parent covariances (using wild-caught females and their laboratory-reared daughters) divided by the geometric mean of the within-trait offspringparent covariances (Falconer, 1989). The usefulness of this estimate depends critically on the magnitude of genotype-environment interaction, as it does not contain either the desired between-trait genetic correlation in nature, or the between-trait genetic correlation in the laboratory. Using the lower bound of heritability in nature $\left(\gamma h_{\mathrm{N}}^{2}\right)$, we can sometimes show that the additive genetic correlation in nature has the same sign as the phenotypic correlation $\left(r_{\mathrm{P}}\right)$. A lower bound of $h_{\mathrm{N}}^{2}$ provides an upper bound for $e_{\mathrm{N}}^{2}\left(=1-h_{\mathrm{N}}^{2}\right)$. If $r_{\mathrm{P}}^{2}>$ $\left(1-\gamma h_{\mathrm{N} x}^{2}\right)\left(1-\gamma h_{\mathrm{N} y}^{2}\right)$, then the environmental correlation between $x$ and $y$ cannot account for the magnitude of their phenotypic correlation (Riska et al., 1989).

All statistical analyses were carried out with SYSTAT 7.0 (Wilkinson, 1997). 
Table 1 Basic statistics for Drosophila mediopunctata wing size (SI), shape (SH) and the angles $\theta_{\mathbf{A}}, \theta_{\mathbf{B}}, \theta_{\mathbf{C}}, \theta_{\mathrm{D}}, \theta_{\mathrm{E}}$ and $\theta_{\mathbf{J}}$ in the wild-caught males and females and in the laboratory-reared $\mathrm{F}_{1} . C V$ is the coefficient of variation. $t$-tests were used to compare males vs. females in nature and females in nature vs. laboratory-reared $\mathrm{F}_{1}$ females

\begin{tabular}{|c|c|c|c|c|c|}
\hline & \multicolumn{3}{|c|}{$\begin{array}{c}\text { Mean } \pm \mathrm{SE} \\
C V\end{array}$} & \multicolumn{2}{|c|}{$t$-test } \\
\hline & \multicolumn{2}{|c|}{ Field } & \multirow{2}{*}{$\begin{array}{l}\text { Laboratory } \\
\text { Female } \\
n=303\end{array}$} & \multirow{2}{*}{$\begin{array}{l}\text { Field } \\
\text { Male vs. } \\
\text { female }\end{array}$} & \multirow{2}{*}{$\begin{array}{c}\text { Female } \\
\text { Field vs. } \\
\text { laboratory }\end{array}$} \\
\hline & $\begin{array}{c}\text { Male } \\
n=163\end{array}$ & $\begin{array}{c}\text { Female } \\
n=135\end{array}$ & & & \\
\hline SI & $\begin{array}{c}47.60 \pm 0.25 \\
0.067\end{array}$ & $\begin{array}{c}54.61 \pm 0.30 \\
0.064\end{array}$ & $\begin{array}{c}58.46 \pm 0.10 \\
0.030\end{array}$ & $17.95 * * *$ & $\begin{array}{r}12.13 * * * \\
8.30 * * *\end{array}$ \\
\hline $\mathrm{SH}$ & $\begin{array}{c}0.4444 \pm 0.0010 \\
0.029\end{array}$ & $\begin{array}{c}0.4480 \pm 0.0012 \\
0.032\end{array}$ & $\begin{array}{c}0.4489 \pm 0.0008 \\
0.033\end{array}$ & $2.41^{*}$ & $\begin{array}{r}0.66 \\
-0.42\end{array}$ \\
\hline$\theta_{\mathbf{J}}$ & $\begin{array}{c}0.2687 \pm 0.0018 \\
0.083\end{array}$ & $\begin{array}{c}0.2774 \pm 0.0017 \\
0.073\end{array}$ & $\begin{array}{c}0.2812 \pm 0.0014 \\
0.086\end{array}$ & $3.19 * *$ & $\begin{array}{c}1.78 \\
-2.29 * *\end{array}$ \\
\hline$\theta_{\mathrm{A}}$ & $\begin{array}{c}0.5048 \pm 0.0024 \\
0.062\end{array}$ & $\begin{array}{c}0.5195 \pm 0.0022 \\
0.051\end{array}$ & $\begin{array}{c}0.5196 \pm 0.0017 \\
0.056\end{array}$ & $4.14 * * *$ & $\begin{array}{r}0.23 \\
-1.30\end{array}$ \\
\hline$\theta_{\mathrm{B}}$ & $\begin{array}{c}2.7848 \pm 0.0021 \\
0.010\end{array}$ & $\begin{array}{c}2.8073 \pm 0.0021 \\
0.009\end{array}$ & $\begin{array}{c}2.8465 \pm 0.0011 \\
0.007\end{array}$ & $7.44 * * *$ & $\begin{array}{r}16.29 * * * \\
3.24 * * *\end{array}$ \\
\hline$\theta_{\mathrm{C}}$ & $\begin{array}{c}3.1426 \pm 0.0014 \\
0.006\end{array}$ & $\begin{array}{c}3.1511 \pm 0.0013 \\
0.005\end{array}$ & $\begin{array}{c}3.1635 \pm 0.0007 \\
0.004\end{array}$ & $4.32 * * *$ & $\begin{array}{l}8.43^{* * *} \\
2.90^{* *}\end{array}$ \\
\hline$\theta_{\mathrm{D}}$ & $\begin{array}{c}3.3238 \pm 0.0016 \\
0.006\end{array}$ & $\begin{array}{c}3.3229 \pm 0.0016 \\
0.006\end{array}$ & $\begin{array}{c}3.3302 \pm 0.0009 \\
0.005\end{array}$ & 0.05 & $\begin{array}{l}4.24^{* * *} \\
2.90^{* *}\end{array}$ \\
\hline$\theta_{\mathrm{E}}$ & $\begin{array}{c}4.3379 \pm 0.0050 \\
0.015\end{array}$ & $\begin{array}{c}4.3307 \pm 0.0053 \\
0.014\end{array}$ & $\begin{array}{c}4.2934 \pm 0.0034 \\
0.014\end{array}$ & 0.86 & $\begin{array}{l}6.16^{* * * *} \\
0\end{array}$ \\
\hline
\end{tabular}

$* P<0.05 ; * *<0.01 ; * * * P<0.001$. Linear measurements were taken in $1 / 55 \mathrm{~mm}$. The angular unit is radians.

\section{Results}

\section{Wild-caught and laboratory-reared flies}

Table 1 shows the basic statistics for the wing traits analysed in wild-caught flies (males and females) and in $\mathrm{F}_{1}$ laboratory females reared at $16.5^{\circ} \mathrm{C}$. The effect of sex was revealed in comparisons between wild-caught males and females; their means differed significantly in most traits $\left(\theta_{\mathrm{D}}\right.$ and $\theta_{\mathrm{E}}$ are the exceptions). A comparison between laboratory-reared females and their wildcaught mothers revealed environmental effects. These effects were significant for size (laboratory flies were larger) and for most angles $\left(\theta_{\mathbf{J}}\right.$ and $\theta_{\mathrm{A}}$ are the exceptions). However, the wing shapes of laboratoryreared females and their wild-caught mothers were not very different.

\section{Variances and heritability}

It is interesting to compare not only the means, but also the phenotypic variances between wild-caught and laboratory females, because they may be increased by environmental variation in natural habitats. The greater effect of the environmental variation on the variation of the wing size than on the wing shape can be observed by comparing the coefficients of variation obtained for the wild-caught females and the laboratory-reared ones (Table 1). These results suggest that the natural environment is more variable than the laboratory environment, and that size is strongly affected by environmental variation. We also observed heterogeneity between wild and laboratory estimates of the coefficients of variation for $\theta_{\mathrm{J}}, \theta_{\mathrm{B}}, \theta_{\mathrm{C}}$ and $\theta_{\mathrm{D}}$.

The estimates of natural heritabilities are shown in Table 2 . SH, $\theta_{\mathrm{C}}, \theta_{\mathrm{D}}$ and $\theta_{\mathrm{E}}$ showed a high heritability in the field as indicated in both the cross-environmental $\left(2 b_{(\mathrm{Ol} . \mathrm{Pn})}\right)$ and the lower bound $\left(\gamma^{2} h_{\mathrm{N}}^{2}\right)$ estimates. Concerning these traits, the $2 b_{(\mathrm{Ol} . \mathrm{Pn})} / \gamma^{2} h_{\mathrm{N}}^{2}$ ratio $(k)$ was very close to one suggesting an equivalence of the additive genetic variances between environments and the absence of genotype-environment interactions (Riska et al., 1989). However, as natural heritability estimates were obtained by regressing offspring on mothers, we cannot discard the possibility that $\mathrm{SH}, \theta_{\mathrm{C}}, \theta_{\mathrm{D}}$ and $\theta_{\mathrm{E}}$ are affected by cytoplasmic inheritance. 
Table 2 Heritability estimates of Drosophila mediopunctata wing traits. One hundred and six (106) families were studied, except for the cross-environment regression, where the number of families was 135

\begin{tabular}{lccccrrr}
\hline & $V_{\mathrm{Pn}}$ & $V_{\mathrm{Pl}}$ & \multicolumn{1}{c}{$C O V_{\mathrm{FS}}$} & \multicolumn{1}{c}{$t_{\mathrm{L}}$} & $2 b_{(\mathrm{Ol} . \mathrm{Pn})}$ & $\gamma^{2} h_{\mathrm{N}}^{2}$ & $|k|$ \\
\hline SI & 10.97 & 3.51 & 0.95 & $0.16 \pm 0.06^{*}$ & $-0.07 \pm 0.07$ & 0.05 & 1.4 \\
SH & $2.2 \times 10^{-4}$ & $2.2 \times 10^{-4}$ & $13.45 \times 10^{-5}$ & $0.30 \pm 0.07^{* * *}$ & $0.62 \pm 0.13^{* * *}$ & 0.63 & 1.0 \\
$\theta_{\mathrm{J}}$ & $4.1 \times 10^{-4}$ & $5.5 \times 10^{-4}$ & $-6.33 \times 10^{-5}$ & $-0.05 \pm 0.07$ & $-0.07 \pm 0.15$ & -0.03 & 2.1 \\
$\theta_{\mathrm{A}}$ & $6.9 \times 10^{-4}$ & $6.7 \times 10^{-4}$ & $5.54 \times 10^{-5}$ & $0.04 \pm 0.07$ & $0.03 \pm 0.14$ & 0.01 & 3.0 \\
$\theta_{\mathrm{B}}$ & $6.4 \times 10^{-4}$ & $3.9 \times 10^{-4}$ & $2.77 \times 10^{-4}$ & $0.35 \pm 0.07^{* * *}$ & $0.17 \pm 0.12$ & 0.07 & 2.4 \\
$\theta_{\mathrm{C}}$ & $2.4 \times 10^{-4}$ & $1.5 \times 10^{-4}$ & $4.75 \times 10^{-5}$ & $0.17 \pm 0.08^{*}$ & $0.22 \pm 0.11^{*}$ & 0.25 & 0.9 \\
$\theta_{\mathrm{D}}$ & $3.6 \times 10^{-4}$ & $3.1 \times 10^{-4}$ & $2.37 \times 10^{-4}$ & $0.46 \pm 0.07^{* * *}$ & $0.56 \pm 0.12^{* * *}$ & 0.47 & 1.2 \\
$\theta_{\mathrm{E}}$ & $4.1 \times 10^{-3}$ & $2.9 \times 10^{-3}$ & $2.45 \times 10^{-3}$ & $0.35 \pm 0.07^{* * *}$ & $0.55 \pm 0.13^{* * *}$ & 0.50 & 1.1 \\
\hline
\end{tabular}

$V_{\mathrm{Pn}}$, phenotypic variance in nature; $V_{\mathrm{Pl}}$, phenotypic variance in the laboratory; $C O V_{\mathrm{FS}}$, covariance of full-sibs in the laboratory; $t_{\mathrm{L}}$, intraclass correlation coefficient of full-sibs; $2 b_{(\mathrm{Ol} . \mathrm{Pn})}$, heritability estimate in the field by the regression coefficient of laboratory-reared females on their wild-caught mothers; $\gamma^{2} h_{\mathrm{N}}^{2}=1$ lower bound heritability in nature $=4 b^{2}$ (Ol.Pn) $\left(V_{\mathrm{Pn}} / C O V_{\mathrm{FS}}\right) ; k=2 b_{(\mathrm{Ol} . \mathrm{Pn})} / \gamma^{2} h_{\mathrm{N}}^{2}$. See text for explanations.

${ }^{*} P<0.05 ; * * P<0.01 ; * * * P<0.001$.

On the other hand, for SI, $\theta_{\mathrm{J}}, \theta_{\mathrm{A}}$ and $\theta_{\mathrm{B}}$, no conclusion could be drawn on the accuracy of the value of natural heritability from offspring-parent regression across the two environments $(k>1)$. These estimates could be biased by differences between the additive genetic variance in nature and in the laboratory and by genotype-environment interactions. Anyway, the lower bounds for heritability estimated in nature can still be considered, being less than 0.07 for all of them.

\section{Phenotypic and genetic correlation matrices}

Table 3 shows the phenotypic correlation coefficient $\left(r_{\mathrm{P}}\right)$ among wing traits. The results of the PCA applied to these matrices are shown in Fig. 2. Looking for a general pattern, we can recognize a positive correlation between $\mathrm{SH}, \theta_{\mathrm{D}}$ and $\theta_{\mathrm{E}}$, contrasting with a negative correlation with $\theta_{\mathrm{B}}$. This suggests that there is a part of the variation of the wing morphology characterized by the fact that when the wings become longer (the ratio $b / a$ decreases), the second vein gets closer to the tip of the wing $\left(\theta_{\mathbf{B}}\right.$ increases), as also do the fourth and fifth veins $\left(\theta_{\mathrm{D}}\right.$ and $\theta_{\mathrm{E}}$ decrease; notice that they are in the third quadrant of the ellipse). Moreover, we also observed a gradient in the magnitude of the correlation coefficients between $\theta_{\mathrm{B}}, \theta_{\mathrm{C}}, \theta_{\mathrm{D}}$ and $\theta_{\mathrm{E}}$. For example, changes in the placement of the second longitudinal wing vein $\left(\theta_{\mathrm{B}}\right)$ are highly positively correlated with changes in the placement of the third one $\left(\theta_{\mathrm{C}}\right)$. The correlation decreases in relation to the fourth longitudinal vein, being negatively correlated with the fifth one. A high positive correlation between $\theta_{\mathbf{J}}$ and $\theta_{\mathrm{A}}$ was also observed. However, the variation in the wing size was distributed in different ways in the different analyses.

Although there were significant phenotypic correlations between many of the traits analysed, few significant genetic correlations were detected. The first approach, which applies the usual formula for measuring genetic correlation between traits, detected a positive correlation between $\theta_{\mathrm{D}}$ and $\theta_{\mathrm{E}}$ and between each of these and $\mathrm{SH}$, all of which were of the same sign observed in the phenotypic correlation. The values obtained are: $\mathrm{SH} \times \theta_{\mathrm{D}}=0.36 \pm 0.13 ; \quad \mathrm{SH} \times \theta_{\mathrm{E}}=$ $0.45 \pm 0.12$; and $\theta_{\mathrm{D}} \times \theta_{\mathrm{E}}=0.45 \pm 0.13$. For $\theta_{\mathrm{C}}$ and $\mathrm{SH}$, we have obtained a high negative genetic correlation $(-0.72 \pm 0.11)$, which contrasts with the absence of significant values for the phenotypic results. Using the alternative method, we estimated the maximum environmental contribution to the phenotypic correlation $\left(r_{\mathrm{P}}\right)$. It showed that, for $\mathrm{SH}$ and $\theta_{\mathrm{E}}$, as well as for $\theta_{\mathrm{C}}$ and $\theta_{\mathrm{D}}$, the environmental correlation cannot account for the magnitude of $r_{\mathrm{P}}$.

\section{Discussion}

The fitting of an ellipse to Drosophila wings has proved to be an efficient method for describing their variation. It allows us to identify and isolate variation in the wing outline and in the position of veins on the wing blade. The analyses of the parameters obtained by the adjusted ellipses show that wing traits in Drosophila produce different patterns of response when subjected to environmental variation. Wing size (SI) and the second longitudinal wing vein were the most sensitive traits, being influenced in their means and variances by environmental changes. The variances of SI, $\theta_{\mathrm{B}}$ and $\theta_{\mathrm{C}}$ are greater in wild-caught females than in their daughters reared in the laboratory. To a certain extent, this is expected as a response to the reduction in environmental variation in the laboratory. Other authors, using characters related to body size in D. melanogaster, have 
Table 3 Estimates of phenotypic correlations of Drosophila mediopunctata wing traits

\begin{tabular}{|c|c|c|c|c|c|c|c|c|}
\hline & & & & Wild-caught males & & & & \\
\hline Measure & SI & SH & $\theta_{\mathbf{J}}$ & $\theta_{\mathrm{A}}$ & $\theta_{\mathrm{B}}$ & $\theta_{\mathrm{C}}$ & $\theta_{\mathrm{D}}$ & \\
\hline SI & 1 & & & & & & & SI \\
\hline $\mathrm{SH}$ & 0.09 & 1 & & & & & & SH \\
\hline$\theta_{\mathbf{J}}$ & 0.04 & 0.00 & 1 & & & & & $\theta_{\mathbf{J}}$ \\
\hline$\theta_{\mathrm{A}}$ & 0.13 & 0.03 & $0.81 * * *$ & 1 & & & & $\theta_{\mathrm{A}}$ \\
\hline$\theta_{\mathrm{B}}$ & 0.14 & $-0.26^{* *}$ & 0.15 & $0.29 * * *$ & 1 & & & $\theta_{\mathrm{B}}$ \\
\hline$\theta_{\mathrm{C}}$ & 0.02 & -0.09 & $0.18^{*}$ & $0.22 * *$ & $0.49 * * *$ & 1 & & $\theta_{\mathrm{C}}$ \\
\hline$\theta_{\mathrm{D}}$ & 0.08 & $0.37 * * *$ & 0.08 & 0.07 & $0.19^{*}$ & $0.64 * * *$ & 1 & $\theta_{\mathrm{D}}$ \\
\hline$\theta_{\mathrm{E}}$ & $-0.29 * *$ & $0.48^{* * *}$ & $-0.17^{*}$ & $-0.26^{* *}$ & $-0.46 * * *$ & 0.01 & $0.28 * *$ & $\theta_{\mathrm{E}}$ \\
\hline Measure & SI & SH & $\theta_{\mathbf{J}}$ & $\begin{array}{l}\text { Wild-caught females } \\
\theta_{\mathrm{A}}\end{array}$ & $\theta_{\mathrm{B}}$ & $\theta_{\mathrm{C}}$ & $\theta_{\mathrm{D}}$ & \\
\hline SI & 1 & & & & & & & SI \\
\hline $\mathrm{SH}$ & $-0.20 *$ & 1 & & & & & & SH \\
\hline$\theta_{\mathbf{J}}$ & 0.04 & 0.11 & 1 & & & & & $\theta_{\mathbf{J}}$ \\
\hline$\theta_{\mathrm{A}}$ & $0.22 *$ & 0.04 & $0.83^{* * *}$ & 1 & & & & $\theta_{\mathrm{A}}$ \\
\hline$\theta_{\mathrm{B}}$ & $0.55^{* * *}$ & $-0.35^{* * *}$ & -0.03 & 0.14 & 1 & & & $\theta_{\mathrm{B}}$ \\
\hline$\theta_{\mathrm{C}}$ & $0.22 *$ & -0.03 & $-0.26^{*}$ & -0.16 & $0.52^{* * *}$ & 1 & & $\theta_{\mathrm{C}}$ \\
\hline$\theta_{\mathrm{D}}$ & 0.07 & $0.20^{*}$ & $-0.22 *$ & $-0.22 *$ & 0.19 & $0.67 * * *$ & & $\theta_{\mathrm{D}}$ \\
\hline$\theta_{\mathrm{E}}$ & $-0.38 * * *$ & $0.44 * * *$ & $-0.21^{*}$ & $-0.39 * * *$ & $-0.37 * * *$ & 0.12 & $0.42 * * *$ & $\theta_{\mathrm{E}}$ \\
\hline & & & & Laboratory females & & & & \\
\hline Measure & SI & SH & $\theta_{\mathbf{J}}$ & $\theta_{\mathrm{A}}$ & $\theta_{\mathrm{B}}$ & $\theta_{\mathrm{C}}$ & $\theta_{\mathrm{D}}$ & \\
\hline SI & 1 & & & & & & & SI \\
\hline SH & -0.01 & 1 & & & & & & SH \\
\hline$\theta_{\mathbf{J}}$ & $0.35^{* * *}$ & -0.05 & 1 & & & & & $\theta_{\mathbf{J}}$ \\
\hline$\theta_{\mathrm{A}}$ & $0.46^{* * *}$ & -0.10 & $0.76^{* * *}$ & 1 & & & & $\theta_{\mathrm{A}}$ \\
\hline$\theta_{\mathrm{B}}$ & $0.20^{*}$ & $-0.46^{* * *}$ & 0.11 & $0.22 * *$ & 1 & & & $\theta_{\mathrm{B}}$ \\
\hline$\theta_{\mathrm{C}}$ & 0.09 & -0.04 & -0.04 & 0.02 & $0.43^{* * *}$ & 1 & & $\theta_{\mathrm{C}}$ \\
\hline$\theta_{\mathrm{D}}$ & 0.01 & $0.40^{* * *}$ & -0.02 & -0.02 & 0.03 & $0.50 * * *$ & 1 & $\theta_{\mathrm{D}}$ \\
\hline$\theta_{\mathrm{E}}$ & -0.13 & $0.65^{* * *}$ & $-0.25 * *$ & $-0.35 * * *$ & $-0.48 * * *$ & -0.02 & $0.45 * * *$ & $\theta_{\mathrm{E}}$ \\
\hline
\end{tabular}

$* P<0.05 ; * * P<0.01 ; * * * P<0.001$.

described similar results (Coyne \& Beecham, 1987; Robertson, 1987; Gibert et al., 1998).

The phenotypic variation being larger in the field than in the laboratory may explain the low heritability we observed for SI in the former. Our results confirm, as in several previous studies with Drosophila, that the estimates of size heritability in nature are generally low (Prout \& Barker, 1989; Ruiz et al., 1991; Gibert et al., 1998; Bitner-Mathé \& Klaczko, 1999). However, if genotype-by-environment interactions $(\mathrm{G} \times \mathrm{E})$ are present, one will obtain an underestimate of $h^{2}$ if one uses this experimental design (Lande, in Coyne \& Beecham, 1987; Riska et al., 1989). Both factors may contribute to the low estimated heritabilities. There is evidence of a $\mathrm{G} \times \mathrm{E}$ interaction for wing size and for other characters related to body size in D. mediopunctata (Bitner-Mathé et al., 1995), in D. aldrichi and D. buzzatii (Barker \& Krebs, 1995), and in Drosophila melanogaster (David et al., 1994; De Moed et al., 1997a,b).
Interestingly, the shape of the wing outline (SH) was less sensitive to environmental changes and exhibited a high heritability in nature. Furthermore, the estimate of its heritability in nature was very close to the broadsense heritability $\left(H_{\mathrm{SH}}^{2}\right)$ estimated in the more homogeneous environment in the laboratory $\left(H_{\mathrm{SH}}^{2}=0.59 \pm\right.$ 0.14 which may be obtained by doubling the intraclass coefficient in Table 2). In another natural population of Drosophila mediopunctata from a locality $1500 \mathrm{~km}$ away, we observed that shape variation had a high heritability in nature, close to or above 0.40 and did not vary significantly temporally. On the contrary, size heritability estimates were nonsignificant in all but one month, when the estimate reached a value of $0.51 \pm 0.11$ (Bitner-Mathé \& Klaczko, 1999).

The experimental design carried out in the present study was necessary to measure natural heritability; however, it was inconclusive in many aspects. An important factor is that for all the wing traits analysed, 

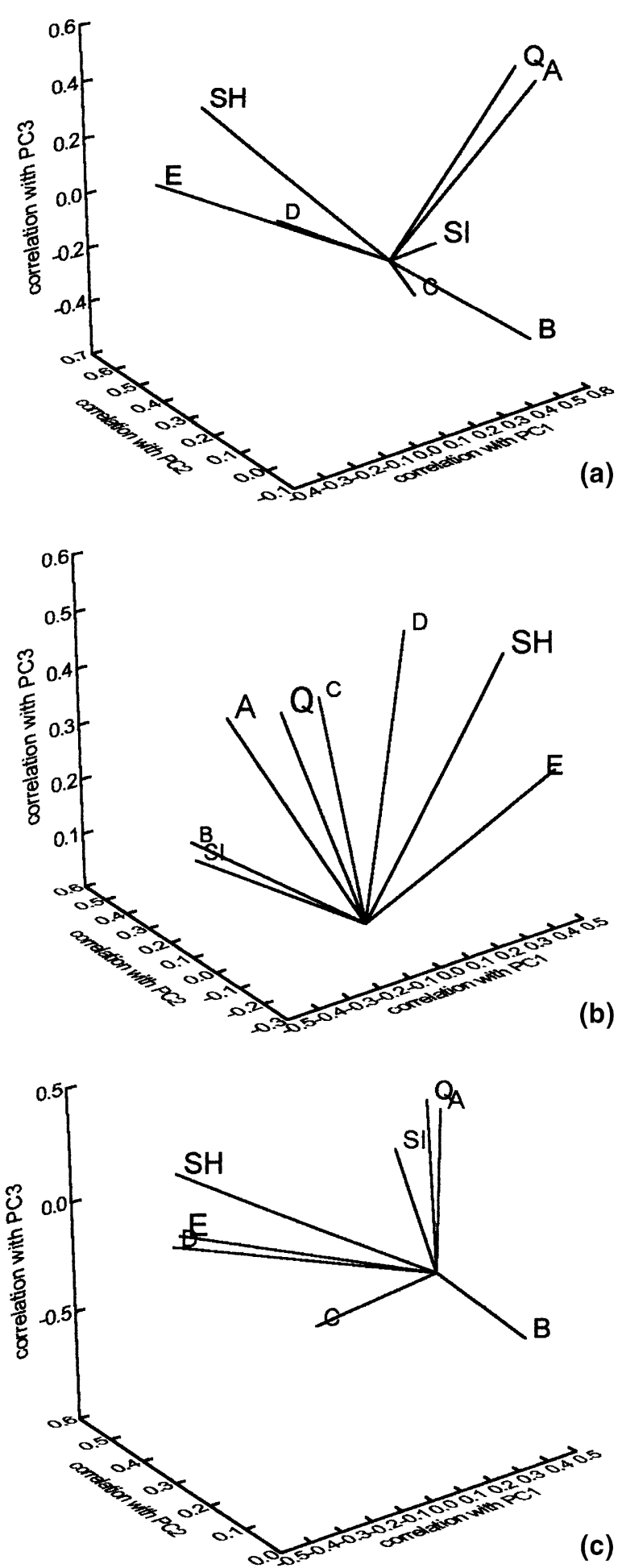

Fig. 2 Corresponding correlations of each character with the first three principal components of correlation matrices. (a) Wild-caught male Drosophila mediopunctata; (b) Wild-caught females; and (c) $\mathrm{F}_{1}$ daughters reared in the laboratory. SI: wing size $(\sqrt{ } a b)$; $\mathrm{SH}$ : wing shape $(b / a)$; A, B, C, D, E and J: angles that determine the positions of the wing veins - the symbol $\theta$ was omitted. except for size, this was the first time that heritability has been estimated. We do not yet have laboratory-controlled studies to help us to understand the effects of different factors on the variation of these traits. For example, because heritabilities were estimated by regressing mothers and daughters, or by intraclass correlation, we cannot rule out the possibility that some of the high heritability observed resulted from the influence of cytoplasmic inheritance. In D. melanogaster, applying Fourier analysis to describe the wing outline, Cavicchi et al. (1991) concluded that the effect of cytoplasm on the trait was as great as that of the chromosomes. A laboratory experiment may clarify this question and may also provide more informative estimates of genetic correlations.

Another point to investigate is whether wing-shape related traits have an adaptive importance in D. mediopunctata, as was suggested for these traits in D. melanogaster (Cavicchi et al., 1991; Imasheva et al., 1995; Pezzoli et al., 1997). Moreover, the results suggest that size and shape have different genetic properties which may lead to different patterns of evolution.

We observed a consistent pattern of correlation among some wing traits that may induce or constrain changes in Drosophila wings. We emphasize the high positive correlation between the wing shape $(\mathrm{SH})$, the fourth $\left(\theta_{\mathrm{D}}\right)$ and fifth $\left(\theta_{\mathrm{E}}\right)$ longitudinal wing veins against a negative correlation of these traits with the second longitudinal vein $\left(\theta_{\mathrm{B}}\right)$, that is, as the wing shape gets longer, the apices of the second and fifth veins become closer to each other. Moreover, there is a gradient of correlation among longitudinal wing veins, suggesting that changes in the position of each wing vein are influenced by changes occurring in the nearest ones. For example, although the third and fourth veins are highly correlated, they are also influenced by antagonistic changes in the more external ones described by $\theta_{\mathrm{B}}$ and $\theta_{\mathrm{E}}$.

The correlations described above may express patterns of underlying genetic control. We have obtained evidence that the positive correlation between wing shape and the position of the fourth and fifth wing veins and between the third and fourth veins are partially explained by their additive genetic correlation. Although we did not observe any significant additive genetic correlation including the second wing vein, such a correlation may be present. The genetic correlation, as well as the natural heritability, using a mother from the field and an $F_{1}$ reared in laboratory, would be underestimated if the traits are affected by $\mathrm{G} \times \mathrm{E}$ interactions. A comparison between genetic and phenotypic correlations reveals a close match between the two measures for morphological traits in different organisms (Cheverud, 1982; Roff, 1995; Waitt \& Levin, 1998). So, other 
phenotypic correlations observed between wing traits may also have a genetic component that we could not detect. In particular, wing shape and the position of wing veins have consistent phenotypic correlations with each other, which suggests their parallelism with genetic correlation.

There are compartments in the wing of Drosophila that reflect certain developmental restrictions (Garcia-Bellido $\&$ Celis, 1992). The second and the third longitudinal wing veins are included in the anterior compartment, whereas the fourth and fifth are included in the posterior one. Thompson et al. (1980), studying the vein placement in a variety of wing-vein mutants, observed that the position of a vein can be displaced to compensate for loss of a vein in a nearby part of the wing. They noticed compensations affecting vein pairs in the same wing compartment, such as the second and third longitudinal veins, but also examples of vein interaction between the third and fourth longitudinal ones, which are located in different compartments of the wing. So, it is possible that a certain proportion of the correlated responses observed results from mechanisms of developmental homeostasis or geometric constraints, in which they automatically provide morphological compensation.

D'Arcy Thompson (1917) illustrated how the shape of one species can be derived from another by a simple geometric transformation. We might imagine starting from a circular wing and then increasing the major axis. Some correlations among the angles that determine the wing vein positions are predictable by such a process, but others are not. In other words, a general elongation might involve specific genes or developmental constraints, whereas other genes and/or environmental factors would act differently.

\section{Acknowledgements}

It is a pleasure to thank Vera Valente-Gaiesky for her hospitality and logistical facilities she provided while we collected at Morro Santana, Carlos Vilela and Lyria Mori for valuable help with computation and laboratory facilities when B. Bitner-Mathé was at the Universidade de São Paulo, and Antonio B. Carvalho for many suggestions during this work and helpful criticisms on the manuscript at various stages. We are also grateful to A. Solé-Cava and anonymous reviewers for valuable comments on the manuscript. This work has been supported by the following granting agencies: Fundação Universitária José Bonifácio (FUJB-UFRJ), Coordenação de Aperfeiçoamento de Pessoal de Nível Superior (CAPES), Conselho Nacional de Desenvolvimento Científico e Tecnológico (CNPq), Fundação de Amparo à Pesquisa do Estado de São Paulo
(FAPESP) e Fundo de Apoio ao Ensino e Pesquisa da UNICAMP (FAEP-UNICAMP).

\section{References}

BARKER, J. S. F. AND KREBS, R. A. 1995. Genetic variation and plasticity of thorax length and wing length in Drosophila aldrichi and D. buzzatii. J. Evol. Biol., 8, 689-709.

BECKER, W. A. 1992. Manual of Quantitative Genetics, 5th edn. Academic Enterprises, Pullman, WA.

BITNER-MATHÉ, B. C. AND KLACZKO, L. B. 1999. Size and shape heritability in natural populations of Drosophila mediopunctata: temporal and microgeographical variation. Genetica, in press.

CAVICCHI, S., GIORGI, G., NATALI, V. AND GUERRA, D. 1991. Temperature-related divergence in experimental populations of Drosophila melanogaster. III. Fourier and centroid analysis of wing shape and relationship between shape variation and fitness. J. Evol. Biol., 4, 141-159.

Cheverud, J. M. 1982. Phenotypic, genetic, and environmental morphological integration in the cranium. Evolution, 36, 499-516.

COYNE, J. A. AND BEECHAM, E. 1987. Heritability of two morphological characters within and among natural populations of Drosophila melanogaster. Genetics, 117, 727-737.

D'ARCY THOMPSON, D. w. 1917. On Growth and Form. Cambridge University Press, Cambridge.

DAVID, J. R., MORETEAU, B., GAUTHIER, J. P., PÉTAVY, G., STOCKEL, A. AND IMASHEVA, A. G. 1994. Reaction norms of size characters in relation to growth temperature in Drosophila melanogaster: an isofemale lines analysis. Génét. Sel. Évol., 26, 229-251.

DE MOED, G. H., DE JONG, G. AND SCHARLOO, w. 1997a. The phenotypic plasticity of wing size in Drosophila melanogaster: the cellular basis of its genetic variation. Heredity, 79, 260-267.

DE MOED, G. H., DE JONG, G. AND SCHARLOO, W. 1997. Environmental effects on body size variation in Drosophila melanogaster and its cellular basis. Genet. Res., Camb., 70, 35-43.

FALCONER, D. S. 1989. Introduction to Quantitative Genetics, 3rd edn. Longman, Harlow, Essex.

GARCIA-BELlido, A. AND CELIS, J. F. 1992. Developmental genetics of the venation pattern of Drosophila. Ann. Rev. Genet., 26, 277-304.

GIBERT, P., MORETEAU, B., MORETEAU, J. AND DAVID, J. R. 1998. Genetic variability of quantitative traits in Drosophila melanogaster (fruit fly) natural populations: analysis of wild-living flies and of several laboratory generations. Heredity, 80, 326-335.

GROMKO, M. H., NEWPORT, M. E. A. AND KORTIER, M. G. 1984. Sperm dependence of female receptivity to remating in Drosophila melanogaster. Evolution, 38, 1273-1282.

GUPTA, A., P. AND LEWONTIN, R. C. 1982. A study of reaction norms in natural populations of Drosophila pseudoobscura. Evolution, 36, 934-948.

IMASHEVA, A. G., BUBLI, O. A., LAZEBNY, O. E. AND ZHIVOTOVSKY, L. A. 1995. Geographic differentiation in wing shape in Drosophila melanogaster. Genetica, 96, 303-306. 
KlACZKO, L. B. 1995. Population Genetics of Drosophila mediopunctata. In: Levine, L. (ed.) Genetics of Natural Populations. The Continuing Importance of Theodosius Dobzhansky, pp. 140-153. Columbia University Press, New York.

KLACZKO, L. B. AND BITNER-MATHÉ, B. C. 1990. On the edge of a wing. Nature, 346, 231.

LANDE, R. AND ARNOLD, S. J. 1983. The measurement of selection on correlated characters. Evolution, 34, 292-305.

NEFF, N. A. AND MARCuS, L. F. 1980. A Survey of Multivariate Methods for Systematics. Privately published, New York.

PEZZOLI, M. C., GUERRA, D., GIORGI, G., GAROIA, F. AND CAVICCHI, S. 1997. Developmental constraints and wing shape variation in natural populations of Drosophila melanogaster. Heredity, 79, 572-577.

PFRIEM, P. 1983. Latitudinal variation in wing size in Drosophila subobscura and its dependence on polygenes of chromosome O. Genetica, 61, 221-232.

POWELL, J. R. 1974. Temperature-related genetic divergence in Drosophila size. J. Hered., 65, 257-258.

PREvosti, A. 1955. Geographical variability in quantitative traits in populations of Drosophila subobscura. Cold Spring Harb. Symp. Quant. Biol., XX, 294-299.

PROUT, T. AND BARKER, J. S. F. 1989. Ecological aspects of the heritability of body size in Drosophila buzzatii. Genetics, 123, 803-813.

RISKA, B., PROUT, T. AND TURELLI, M. 1989. Laboratory estimates of heritabilities and genetic correlations in nature. Genetics, 123, 865-871.
ROBERTSON, F. W. 1987. Variation of body size within and between wild populations of Drosophila buzzatii. Genetica, 72, 111-125.

ROFF, D. A. 1995. The estimation of genetic correlations from phenotypic correlations: a test of Cheverud's conjecture. Heredity, 74, 481-490.

Ruiz, A., SANTOS, M., BARbadilla, A., QUEZADA-DAZ, J. E., HASSON, E. AND FONTDEVILA, A. 1991. Genetic variance for body size in a natural population of Drosophila buzzatii. Genetics, 128, 739-750.

THOMPSON, J. N. JR, TONEY, J. V. AND SCAEFER, B. 1980. Pattern compensation in Drosophila wing vein development. Heredity, 44, 93-102.

VAL, F. C., VILELA, C. R. AND MARQueS, M. D. 1981. Drosophilidae of the Neotropical Region. In: Ashburner, M., Carson, H. L. and Thompson, J. N. JR (eds) Genetics and Biology of Drosophila, vol. 3a, pp. 123-168. Academic Press, London.

WAITT, D. E. AND LEVIN, D. A. 1998. Genetic and phenotypic correlations in plants: a botanical test of Cheverud's conjecture. Heredity, 80, 310-319.

WEIGENSBERG, I. AND ROFF, D. A. 1996. Natural heritabilities: can they be reliably estimated in the laboratory? Evolution, 50, 2149-2157.

WILKINSON, L. 1997. systat for Windows, version 7. SPSS Inc., Chicago. 